\title{
MICROSCOPY TECHNIQUES FOR INVESTIGATING NUTRITIONAL PROPERTIES OF CEREALS AND THEIR TRANSFORMATION INTO FOODSTUFFS
}

\author{
PAOLINO NINFALI (*), ANNA PANATO $(* *)$, \\ FEDERICA BORTOLOTTI $(* *)$, LAURA VALENTINI (*), PIETRO GOBBI $(*)$
}

SuNTO. - Questo lavoro riguarda la combinazione della microscopia ottica (OM) e della microscopia elettronica a scansione ambientale coniugata con la spettroscopia a dispersione di energia (ESEM-EDS) nella caratterizzazione anatomica e funzionale della cariosside dei cereali, al fine di guidare la tecnologia di trasformazione e conservare $\mathrm{i}$ nutrienti nelle farine e nei loro prodotti derivati. Con l'OM abbiamo analizzato sezioni di cariossidi colorate con Tricromica di Azan, Acido Periodico Shiff (PAS) e Blu di Toluidina. Queste tecniche consentono la caratterizzazione degli strati aleuronici dei cereali con i loro globuli proteici e i granuli di amido di dimensione variabile nell'endosperma. La OM in fluorescenza consente di localizzare i composti fenolici e le fibre solubili, in particolare i $\beta$-glucani di avena e orzo, con l'aiuto del colorante Calcoflour white. L'ESEM-EDS non richiede stabilizzazione chimica o inclusione dei campioni e le strutture sono visualizzate in condizioni naturali. Con l'ausilio dell'ESEM-EDS, abbiamo localizzato i globoidi proteici dell'aleurone, il germe con il suo strato depleto e i granuli di amido, con la loro composizione in elementi chimici. Riferendosi all'aspetto nutrizionale, l'analisi microscopica ha sottolineato la più alta bioaccessibilità nei granuli di amido del farro. A livello tecnologico, orzo e avena si sono dimostrati più adatti del farro per i processi di perlatura e maltaggio, a causa delle loro più spesse e robuste pareti cellulari.

$* * *$

ABSTRACT. - This review focuses on the combination of optical microscopy $(\mathrm{OM})$ and Environmental Scanning Electron Microscopy-Energy Dispersive Spectroscopy (ESEM-EDS) in the anatomical and functional characterization of the cereal caryopsis in order to drive the technology of transformation as well as to save the nutrients in the flours and their derived products. With OM, we analyzed caryopsis sections stained

(*) Dipartimento di Scienze Biomolecolari, Università degli Studi di Urbino

"Carlo Bo", Urbino, Italia. E-mail: pietro.gobbi@uniurb.it

${ }^{(* *)}$ Dipartimento di Diagnostica e Salute Pubblica, Università degli Studi di Verona, Verona, Italia. 
with Azan Trichrome, Periodic Acid Shiff (PAS) and Toluidine blue staining. These techniques allowed the characterization of the aleuronic layers with their protein globoids and starch granules of variable dimensions in the endosperm. Fluorescence $\mathrm{OM}$ allowed to evidence phenolic compounds and soluble fibers, in particular the $\beta$-glucan of oat and barley, with the aid of the dye Calcoflour white. ESEM-EDS does not require fixation or embedding of the samples, and the structures are visualized under natural conditions. By means of ESEM-EDS, we localized protein globoids, the germ with the depleted layer (which connects the germ to the endosperm) and the starch granules with their qualitative elemental composition. Referring to nutrition, microscopic analysis highlights the higher bioaccessibility of einkorn wheat starch granules during digestion. At the technological level, barley and oat are more suitable than einkorn for pearling and malting, due to their thicker and more robust cell walls.

\section{INTRODUCTION}

Cereals comprise a number of monocotyledon plants belonging to the Gramineae family, cultivated all over the world as the main source of carbohydrates and proteins. Cereals are also rich in fibers and several micronutrients such as phytosterols, polyphenols, alkylresorcinols and minerals (Fardet, 2010).

The most important cereals for human nutrition are maize, wheat, rice, barley, oat, and rye. One of the most ancient wheat is einkorn wheat, which is now cultivated in Italy (Triticum monococcum) together with the dicoccum variety, called emmer (Triticum dicoccum). All of them may be consumed in grains or milled into flours, that can be mixed with different ingredients and used for bakery, flaked or extruded products, such as pasta (Fardet, 2010).

The structure of the cereal caryopses consists of three main parts: the aleurone layer, the endosperm and the germ.

The germ (or embryo) is located at the basal part of the caryopsis. At the structural level, the embryo is made of three tissue layers: the scutellum, the suspensor and the embryonal axis. The scutellum and the suspensor are formed by cells devoted to nutrient storage. The cells of the embryonal axis are committed to root formation and are surrounded by a coleorhiza, a plumule separated from the endosperm by a so called depleted layer. The depleted layer can easily be broken and therefore the germ is easily lost from the caryopsis during the milling (McKevith, 2004).

The aleurone layer is structurally made of cubic cells enclosed into thick adjacent cell walls, and is protected on the external part by 
the seed coat and the pericarp, both made of dead cells. The aleuronic cells are variable in number, usually one to three layers of nucleated cells are present in the different cereals. These nucleated cells are rich in soluble and insoluble fibers, as well as in vitamins, polyphenols, lignin, phytic acids and minerals. The cells of the aleurone layer are able to tolerate the dehydration level at which the grains are stored (i.e., 10$12 \%$ residual water), and can survive storage for several months (Fardet, 2010).

During germination, with the absorption of water, the aleurone cells release hormones, the protein bodies become lytic vacuoles that grow and synthesize enzymes, which, in sequence, degrade the cell walls, and convert starch and proteins into free sugars and aminoacids, respectively. Moreover, phytases hydrolyze phytin, while lipases separate the triacylglycerols into free fatty acids and glycerol (McKevith, 2004). At the end of germination, the cells of the aleurone layer undergo apoptosis, with DNA cleavage and loss of membrane integrity (Olsen, 2001).

The endosperm that is located below the sub-aleurone layer, in the internal part of the caryopsis, is made of cells transformed into starch bags which are also rich in proteins and fibers. The starch granules are different in size in many cereals. Generally, they are divided into type A, larger granules and type B, smaller granules. In oat and some other cereals, several small granules aggregate into larger granules (Antonini et al., 2018).

The milling of the caryopsis is a very delicate process, which is linked to the nutrient content of the flours (Zielinski and Kozlowska, 2000). The milling industry has grown to improve separation and purification of the endosperm from the bran and the germ, as these components may induce rancidity and fermentation during the storage of flours (McKevith, 2004). In general, the milling process follows these subsequent phases: cleaning, dehulling, conditioning and milling.

Cleaning is performed exploiting differences in size, shape, specific gravity, and air resistance. Debulling is made by air dehullers that subject the grains to a strong centrifugal force thus making the hulls to be completely detached (Antonini et al. 2016, 2017). Conditioning is the process of grain moistening which provides uniform temperature and moisture in order to prevent bran from breaking up, and to improve separation of the floury endosperm (Deora, 2018). Milling is nowadays obtained by roller mills, and includes the breaking and 
reducing phases. Breacking is obtained by sets of corrugated cylinders with progressively finer corrugations: being paired and rotating inwards against each other, corrugated cylinders break the caryopsis into bran, endosperm and germ; the ground material then passes through sifters. In the reducing phase, the separated particulate material is ground by a set of up to 12 smooth grinding-rolls, to produce finer particles called "middlings", that are as free as possible from bran. Middlings are then ground to flour by a smooth roller system. The procedure may be repeated over and over again, moving up and down across the mill until the maximum amount of flour is separated at about $75 \%$ of the wheat kernel (Deora, 2018).

The Italian law classifies the flours based on the sieving rates obtained by milling $100 \mathrm{Kg}$ of grains. As higher this value is, as more bran is present in the flour. From the milling of soft grains four types of flours are obtained: ' 00 ', ' 0 ', ' 1 ', and ' 2 '. The type ' 00 ' is obtained by a $50 \%$ sieving rate. The ' 0 ' type flour usually has a $72-75 \%$ sieving rate. The types 1 and 2 show a $80 \%$ and $85 \%$ sieving rate, respectively (McKevith, 2004).

The products derived from the soft wheat grains are called flours and used for bread and bakery products, whereas those obtained by the durum wheat grains are called semolina and used for extruded products such as pasta.

During the mixing of the flours with water to obtain the dough, the proteins glyadins and glutelines generate the gluten network, that represents the main elastic component in the bakery and pasta products. This network captures the air and the $\mathrm{CO}_{2}$ bubbles, formed during the leaving phase, increasing the volume of the dough. The gluten network is the triggering factor for the celiac disease affecting about $1 \%$ of the population, and possibly of another softer disease called gluten sensitivity which is found in about $10 \%$ of the population (Kasarda et al., 2013). It is believed that the use of ancient grains, like einkorn or emmer, may attenuate the gluten sensitivity symptoms. Therefore, the selection of the grain type and the technical processing are strictly related to nutritional and health aspects, since several nutrients may be lost if the milling technology is not as accurate and mild as necessary.

In fact, many nutrients are contained in the part of the caryopsis which is more vulnerable during grain processing. For instance, the aleurone layer is very rich in polyphenols (Li et al., 2016) which signif- 
icantly contributes to the antioxidant properties of the flours, as well as in tocopherols and tocotrienols (McKevith, 2004). Indeed, the aleurone contains an average amount of lignans, which are powerful antioxidants able to protect against the injurious effect of reactive oxygen species (Liu, 2007). To maintain all these nutrients, the aleurone's flakes blocked by the sifters should be milled furtherly and added to the flour, in order to obtain the whole meal flour, but as it happens usually, the bran with aleurone flakes are retained for long storage and added to white flour only when it is requested for the "fiber-supplemented flours". Such long storage of the bran reduces significantly the nutrients content, due to oxidative and degradative processes (RosaSibakow et al., 2015).

As far as the endosperm of the caryopsis is concerned, the walls of the cells containing starch granules are rich of arabinoxylans in wheat, and of $\beta$-glucans in oat and barley. The $\beta$-glucans are linear polysaccharides made of glucose units linked by $\beta-(1-4)$ bonds and separated by a single $\beta$-(1-3) bond. The $\beta$-glucan show several health protective effects such as the lowering of the plasmatic glucose and cholesterol levels (EFSA Reg. 432/2012) as well as the ability to develop a probiotic effect, by the selective health-improving stimulation of the intestinal microbiome (Gibson and Roberfroid, 1995). Arabinoxylans are made of xylose residues linked by $\beta-1-4$ bonds, and are the major component of the wheat bran: they have the same health-protective effect of $\beta$-glucans, including the probiotic one (Fardet, 2010). It has to be noted that arabinoxylans and $\beta$-glucans are also present in the aleurone and subaleurone layers, at a different extent depending on the cereal type. The germ is very rich in polyunsaturated fatty acids, vitamins and polyphenols (Fardet, 2010).

The new goal of the research is looking for the preservation of $100 \%$ of the wholegrain products: although such an amount is actually theoretical, this would guarantee the presence of all the grain macroand micronutrients, with important benefits for human health. A huge amount of work was done by the EU "Health Grain" project (van der Kamp et al., 2014) to demonstrate that the production of wholegrain flour is possible by a mild technology, and that the complete pool of nutrients can be maintained by means of the strict control of the whole process. The wholegrain flour is defined as "the product of the dehulled grains eliminating only the impurity and minimal amounts of germ and bran" (van der Kamp et al., 2014). 
Therefeore, discriminating wholegrain products from refined grains is nowadays a very important challenge. Analytical methods such as liquid chromatography coupled with the mass spectrometry (LC/MS) are suitable to follow for instance the lipid profile of the bran, germ and endosperm (Geng et al., 2015): this technique allowed identifying 155 lipid compounds, among which the Alkylresorcinols were proved to be the most relevant markers to discriminate wholegrain from refined flours (Geng et al., 2015).

Unfortunately, these analytical methods requires long preparations of the samples, highly specialized analysts, and expensive equipments. Thus alternative methods have been searched for in the attempt to distinguish wholegrain from refined flours, and microscopic analysis is one of the simplest methods which is becoming increasingly important in cereal science (Dornez et al., 2011; Panato et al., 2017). The main reason lies in the fact that by microscopy it is possible to recognize the layers of the cereal caryopsis present in the flour-derived products thus allowing to identify wholegrain flours where part of the structures of the aleurone and germ are maintained; in addition, by the incidence of these fragments it is possible to deduce the quality of the wholegrain flour as well as the technology applied. The nutrient content in the final product can be mostly preserved when the grain processing has been mild, and the microscopic analysis may also be helpful to demonstrate the mild processing of the grains (Fig. 1).

The aim of this review is to show how microscopy analysis may be usefully applied to the technology of transformation, and to nutrition science in the field of cereal-based products.

\section{HISTOMORPHOLOGY OF GRAIN CARYOPSIS BY OPTICAL MICROSCOPY}

For optical microscopy $(\mathrm{OM})$, the staining of the caryopsis cell layers is achieved by preparing $5 \mu \mathrm{m}$ thin sections from paraffin embedded grains ( $T a b .1)$, followed by staining with appropriate conventional dyes. A suitable staining procedure is the Azan trichromic stain, which may be purchased as a commercial kit. The staining is based on the acid-base properties of the tissues: all the acid macromolecules, such as nucleic acids are stained in purple-red, whereas the basic structures react with aniline blue or orange $G$ resulting in a pale orange stain (Panato et al., 2017). 


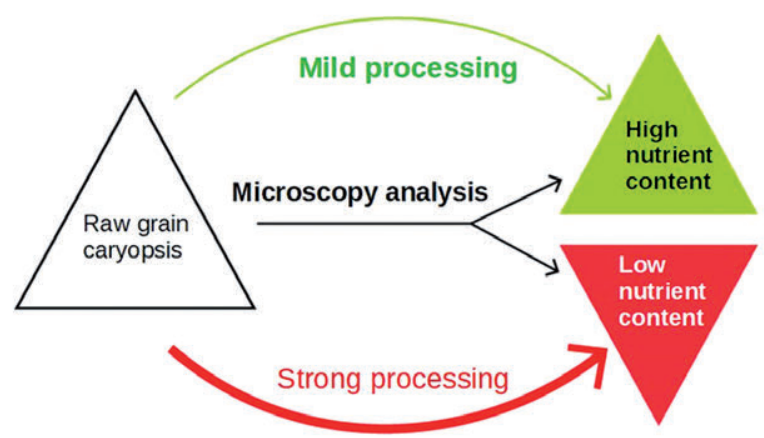

Fig. 1. Graphical visualization of the concept that processing as mild as possible provides final products with higher nutrient contents, whereas the contrary happens with strong processes. The microscopy analysis is useful to evaluate the nutrient losses.

Tab. 1. Microscopy types utilized in the present study.

\begin{tabular}{|c|c|c|}
\hline Microscopy & Sample treatment & Visualization parameters \\
\hline $\begin{array}{l}\text { Bright field optical } \\
\text { microscopy }\end{array}$ & $\begin{array}{l}\text { Fixed, dehydrated and } \\
\text { paraffin embedded } \\
\text { samples. } 5 \mu \text { m sections } \\
\text { cutting. Possible staining. }\end{array}$ & $\begin{array}{l}\text { Use of dyes for conventional or } \\
\text { specific staining of nutrients. } \\
\text { Visible light. } \\
\text { Magnification: } 5-100 \mathrm{x}\end{array}$ \\
\hline Fluorescence microscopy & As above. & $\begin{array}{l}\text { UV light, } 360-380 \mathrm{~nm} \text { excitation; } \\
420-460 \mathrm{~nm} \text { emission. } \\
\text { Magnification: } 5-100 \mathrm{x}\end{array}$ \\
\hline $\begin{array}{l}\text { Environmental Scanning } \\
\text { Electron Microscopy } \\
\text { (ESEM-EDS) }\end{array}$ & $\begin{array}{l}\text { Macroscopic section. } \\
\text { Deposition of sections on } \\
\text { the specimen holder. }\end{array}$ & $\begin{array}{l}\text { Low vacuum, secondary and } \\
\text { backscattered electrons. } \\
\text { Magnification: } 60-50,000 \mathrm{x}\end{array}$ \\
\hline $\begin{array}{l}\text { Atomic Force } \\
\text { Microscopy (AFM) }\end{array}$ & $\begin{array}{l}\text { Small portion of samples } \\
\text { or deparaffined } 5 \mu \mathrm{m} \\
\text { sections. }\end{array}$ & $\begin{array}{l}\text { Tip in dry tapping mode. } \\
\text { Magnification: square areas of } \\
1-50 \mathrm{~nm}\end{array}$ \\
\hline
\end{tabular}

The Periodic Acid - Shiff (PAS) reaction is useful to stain polysaccharides which react with the periodic acid and are oxidized to aldehydes, which in turn react with the Schiff reagent to provide a purplemagenta staining. The Carazzi's Hemalum complex binds the anionic sites of the histone proteins and stain the nuclei blue.

Fig. 2 A-D shows the aleuronic and sub-aleuronic layers of dehulled oat, einkorn wheat, barley and durum wheat, stained with the Azan Trichromic stain. In oat, the aleurone cells are arranged into a single layer 
and stained in purple red. The aleurone granules appear as red fine spotting in the cytoplasm. The nuclei are stained purple, whereas the cell walls are yellow and the whole dead cells of the pericarp are stained in bluegreen. In einkorn wheat, the aleurone is made of a layer of thin-walled cells; thin walls also characterize the endosperm cells. In barley, there are three layers of aleurone cells, with the same staining pattern as in oat. In the endosperm, the starchy granules are represented by white dots, enclosed into grey cell walls. Different dimensions of the starch granules are better distinguishable proceeding towards the center of the caryopsis. In durum wheat, a compact aleurone layer is evident with the endosperm endowed of large and small starch granules (Panato et al., 2017).

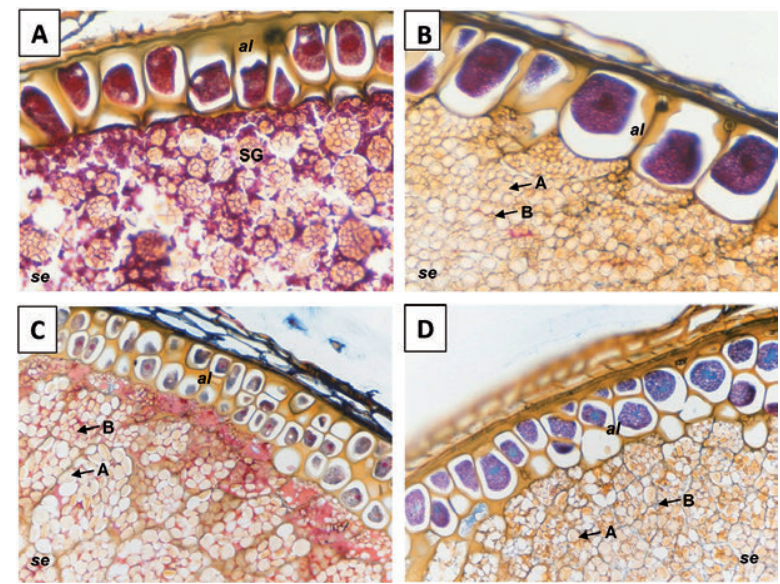

Fig. 2. Aleurone layer in cross sections of grain caryopsis stained with the Azan Trichrome stain kit according to Heidenhain, and observed in a Nikon Coolscope Digital Microscope. A) Debulled oat (20x); B) Einkorn wheat (40x); C) Barley (20x); D) Wheat (20x). Proteins are stained purple, polysaccharides orange, basic substances blue. al, aleurone; se, starchy endosperm; A, type A starchy granules, 15-40 um in diameter; B, type B starchy granules, 5-10 $\mu m$ in diameter; SG, aggregated starchy granules.

Fig. $3 A$-D shows the germ of oat and einkorn wheat stained by the Azan trichromic stain and visualized at two magnifications. This staining allows to distinguish the endosperm, the depleted layer, the scutellum, the primary root, the plumule and the coleoptile. The intrinsic fragility of the depleted layer is evident at higher magnification and demonstrates that the germ may easily detach from the caryopsis under a minimal centrifugal force. 


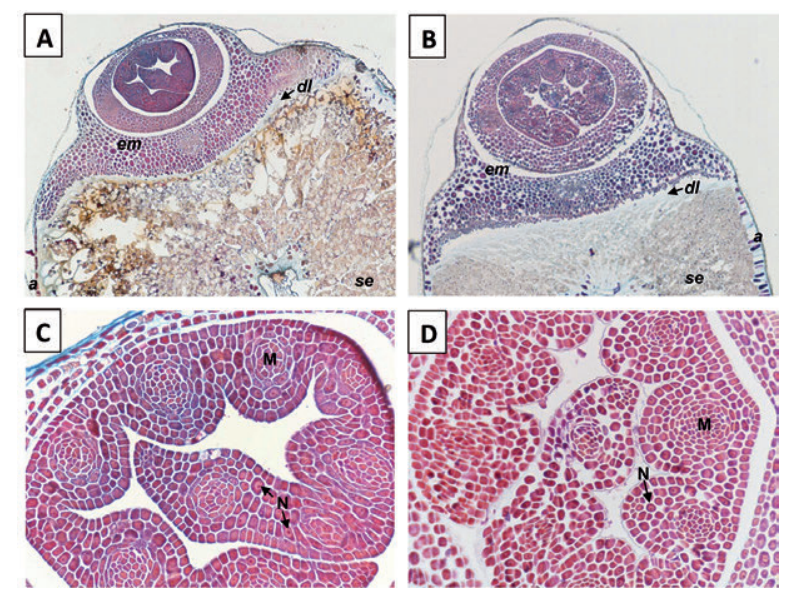

Fig. 3. Embryo in cross sections of grain caryopses stained with the Azan Trichrome stain kit according to Heidenhain, and observed in Nikon Coolscope Digital Microscope. A) Debulled oat (4x); B) Einkorn wheat (4x); C) Debulled oat (20x); D) Einkorn wheat (20x). al, aleurone; se, starchy endosperm; em, embryo; $d l$, depleted layer; $N$, nuclei; $M$, meristematic cells.

\section{EVIDENCING $\beta$-GLUCANS AND POLYPHENOLS BY FLUORESCENCE MICROSCOPY}

Fig. 4 A-D shows oat, einkorn wheat, barley and durum wheat sections stained with Calcofluor white, a fluorescent dye that binds $\beta$-polysaccharides (principally the $\beta$-glucan) and, to a lesser extent, cellulose. The increasing presence of the $\beta$-glucan is revealed by the change from a dark blue to shining azure. A large amount of $\beta$-glucan is observed in the oat and barley endosperm, whereas einkorn wheat and durum wheat exhibit pale staining mainly due to cellulose material and to a very small amount of $\beta$-glucan (Panato et al., 2017).

In Fig. $5 A, B$ the Toluidine blue staining of caryopsis sections of barley and wheat is shown. The cell walls are stained in greenish-blue thus showing that the polyphenols are bound to the cellulose fibers in the cell walls. Polyphenols show in fact their main localization in the aleuronic layer (Panato et al., 2017).

A simpler way to evidence the polyphenols, is to take advantage from their autofluorescence (Fulcher, 1982): unstained sections, when examined in fluorescence microscopy (Tab. 1), show the aleurone layer in brilliant green and the cell walls as a green fluorescing mosaic (Fig. 5 C,D). 

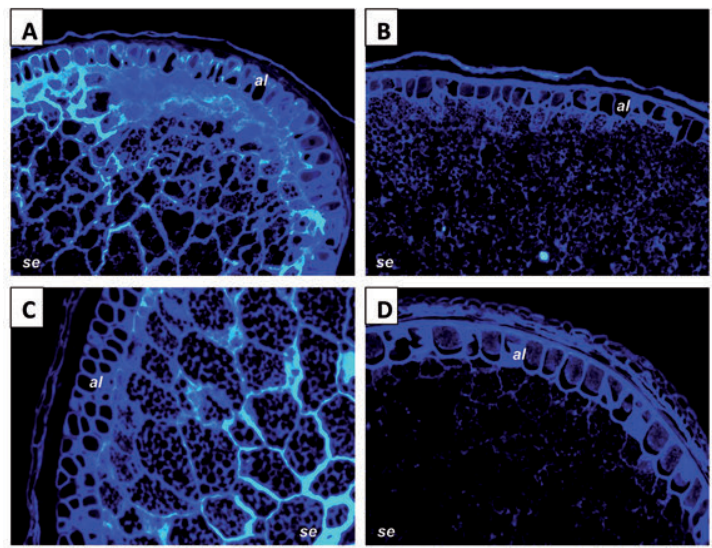

Fig. 4. Aleurone layer in cross sections of grain caryopsis stained with the fluorescent dye, Calcofluor White to detect $\beta$-glucans and analyzed in a fluorescence microscope Axioskop 2 (excitation wavelength, $380 \mathrm{~nm}$; emission wavelength, $440 \mathrm{~nm}$ ). A) Hulled oat; B) Einkorn wheat; C) Barley; D) Wheat. $\beta$-glucans fluoresce light blue. al, aleurone; se, starchy endosperm. 20x magnification.
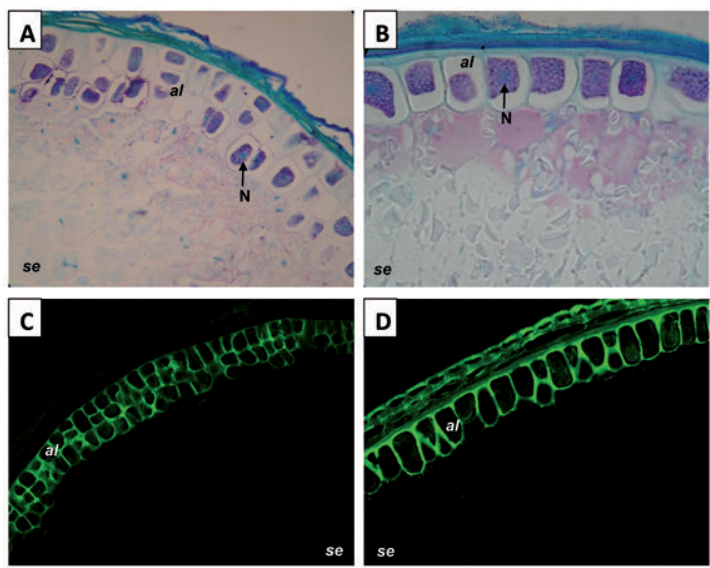

Fig. 5. Aleurone layer in cross sections of grain caryopses stained with Toluidine Blue to detect phenol compounds ( $A$ and B), or showing the autofluorescence of phenol compounds ( $C$ and D). A) Barley; B) Wheat. Sections stained with Toluidine Blue and analyzed by camera Nikon E500 assembled to the microscope Nikon Eclipse E400 at 40x magnification. Phenolics appear light-blue/green; nucleic acid (N) appears blue. al, aleurone; se, starchy endosperm. C) Barley; D) Wheat. Native fluorescence in unstained sections and analyzed by the fluorescence microscope Axioskop 2 at 20x magnification (excitation wavelength $365 \mathrm{~nm}$; emission wavelength $418 \mathrm{~nm}$ ). Phenolics appear green. al, aleurone; se, starchy endosperm. 
MORPHOLOGICAL EVALUATION OF NUTRIENTS BY ESEM-EDS AND AFM MICROSCOPY

When applied to analyze the caryopsis, ESEM-EDS allows to directly evaluate the cell wall thickness, and the density and size of the aleurone protein globoids as well as of the starch granules. Samples are prepared by longitudinally or transversally cutting the seeds, followed by the adhesion of the sections to the specimen holder, by means of a pure carbon bi-adhesive disk. In addition to the morphological analysis, the ESEM combined with the EDS equipment allows to obtain the elemental composition of the investigated cell structures, such as globoids or amyloplasts (Antonini et al., 2018).

Fig. 6 shows the ESEM analysis of the germ of einkorn and barley at low magnification. Fig. $6 \mathrm{~A}, \mathrm{~B}$ provide evidence of the fragile structure of the depleted layer, i.e. the layer connecting the germ to the endosperm. In the opposite germ surface, the link of the germ with the seed coat can be detected, despite the low hydration level of the seed. At higher magnification (Fig. $6 C, D$ ), the proteinaceous content of the germ cells can be easily detected by means of the backscattered electrons detector of the ESEM. By this kind of detection system, the electrondense proteins appear as bright dots compared to the darker signal coming from fats and starches. A different protein distribution pattern between einkorn and barley is shown: in einkorn, the protein dots are regularly distributed within the cells and have constant dimensions whereas in barley, proteins appear as distinct clusters made of heterogeneously sized particles. During milling, the fragile depleted layer is broken and the germ is lost in the sieving together with the seed coat. To avoid nutrient losses, the germ should be collected then milled to finer grinding and added to the remaining flour to obtain wholemeal flours.

Fig. $6 D, F$ show the elemental composition of the protein globoids of two cereals, oat and einkorn after ESEM-EDS analysis. The higher concentration of $\mathrm{Ca}, \mathrm{Mg}$, and $\mathrm{Mn}$ was observed in the aleurone layer, with the protein globoids showing a remarkable concentration of $\mathrm{P}$ due to the presence of phytin. In the oat protein globoids, the $\mathrm{P}$ concentration is higher than in the other cereals and consequently also the phytic acid is increased (data not shown). From the nutritional standpoint, this is a positive feature as the phytic acid (once considered to be an anti-nutritional factor) has recently been indicated as a health-protective compound by Silva and Bracarense (2016). 

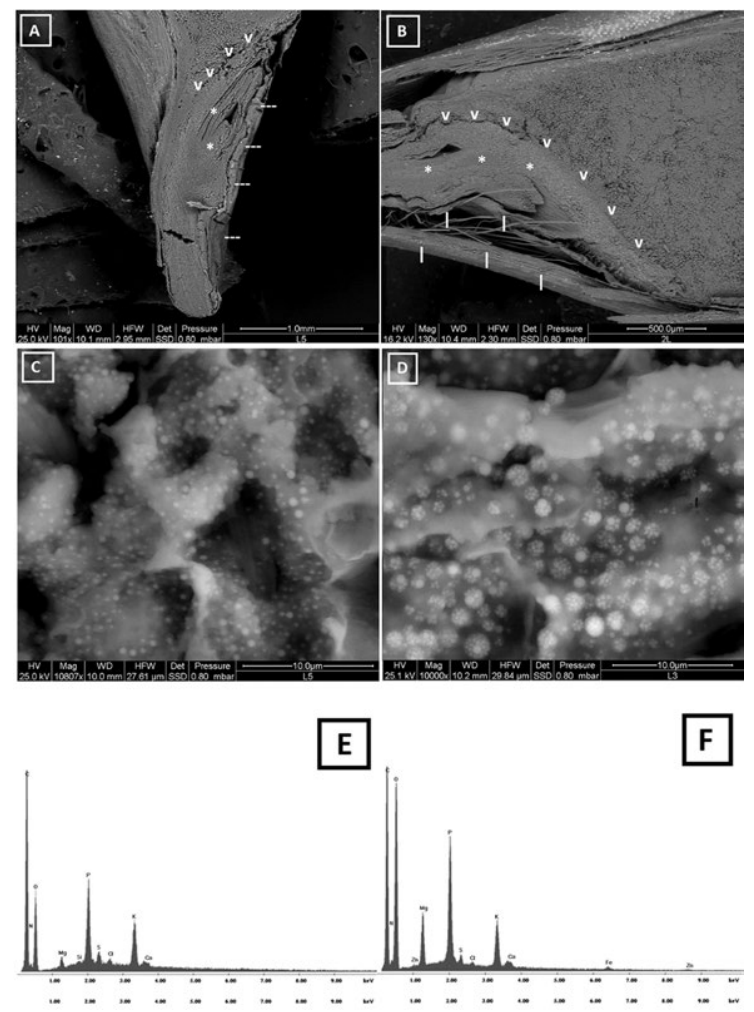

Fig. 6. ESEM and EDS comparison of germs of einkorn $(A, C, E)$ and barley $(B, D, F)$. At ESEM low magnification ( $A, B)$, the germ (asterisk) appears between the seed coat (line) and the depleted layer (arrowhead). The inconsistence of the link with the endosperm, represented by the depleted layer, is evident, while a bond with the seed coat can be detected. At ESEM high magnification $(C, D)$, the protein content of the germ cells becomes evident as bright spots. A different protein distribution pattern is observable. In D, protein globoids appear regularly scattered as round single particles, while in E they appear as clusters formed by dots of different size and brightness. Some differences can be noted also with EDS. Higher amounts of $O, M g$ and $P$ are detectable in barley $(F)$ germ proteins, compared to einkorn (E). Bars: $A=1 \mathrm{~mm} ; B=0.5 \mathrm{~mm}$; $C$ and $D=10 \mu \mathrm{m}$.

Fig. 7 shows the ESEM backscattered electrons analysis of sectioned seeds of einkorn (A), oat (B), barley (C) and wheat (D): the pictures show a general view of the aleurone, comprised between the outer coats and the endosperm. Even at low magnification, the aleurone cells are evident because of their high content of proteins, that correspond to the bright areas of the samples in the backscattered electrons images. 
Einkorn and wheat (Fig. $7 A$ and $D$, respectively) have a single aleurone cell layer whereas a multiple cell layer was observed in barley (Fig. 7 C) and irregular layer in oat (Fig. 7 B). A thick hull layer is still visible in barley and wheat, whereas in the other seeds, only the inner pericarp still remains in situ. The starchy endosperm appears as an abundant, darker granular area in the inner part of the samples.



Fig. 7. ESEM backscattered electrons low magnification analysis of sectioned seeds of einkorn (A), oat (B), barley (C) and wheat (D). The aleurone layer (a) is evident. The protein content can be detected as bright globules, surrounding the darker cell nucleus. The inner pericarp ( $p$ ) is present, in tight relationship with the aleurone. Uniformly gray globules are constituting the starchy endosperm (e), whereas the bull (b) of the outer pericarp is evident in $C$ and $D$ only. Bars: $A, B, C=100 \mu \mathrm{m} ; D=50 \mu \mathrm{m}$.

Fig. 8 shows the aleurone cells at higher magnification. The thinnest cell walls were observed in einkorn wheat (Fig. $8 \mathrm{~A}$ and $B$ ). Cell nuclei are often detectable in einkorn, oat and wheat. In all the samples, the aleurone cells are strictly joined with the inner pericarp layer and with the endosperm. Intracellular protein granules can easily be distinguished from the other cell components. In einkorn, oat and barley, these granules have a round surface bounding an homogeneous bright content, whereas in barley the granules appear contained inside a large, common membrane apparatus. A different structure was observed in the wheat aleurone protein granules which are made of subunits with different size and density; moreover, each single clustered granule appears surrounded by a own semitransparent membrane. 


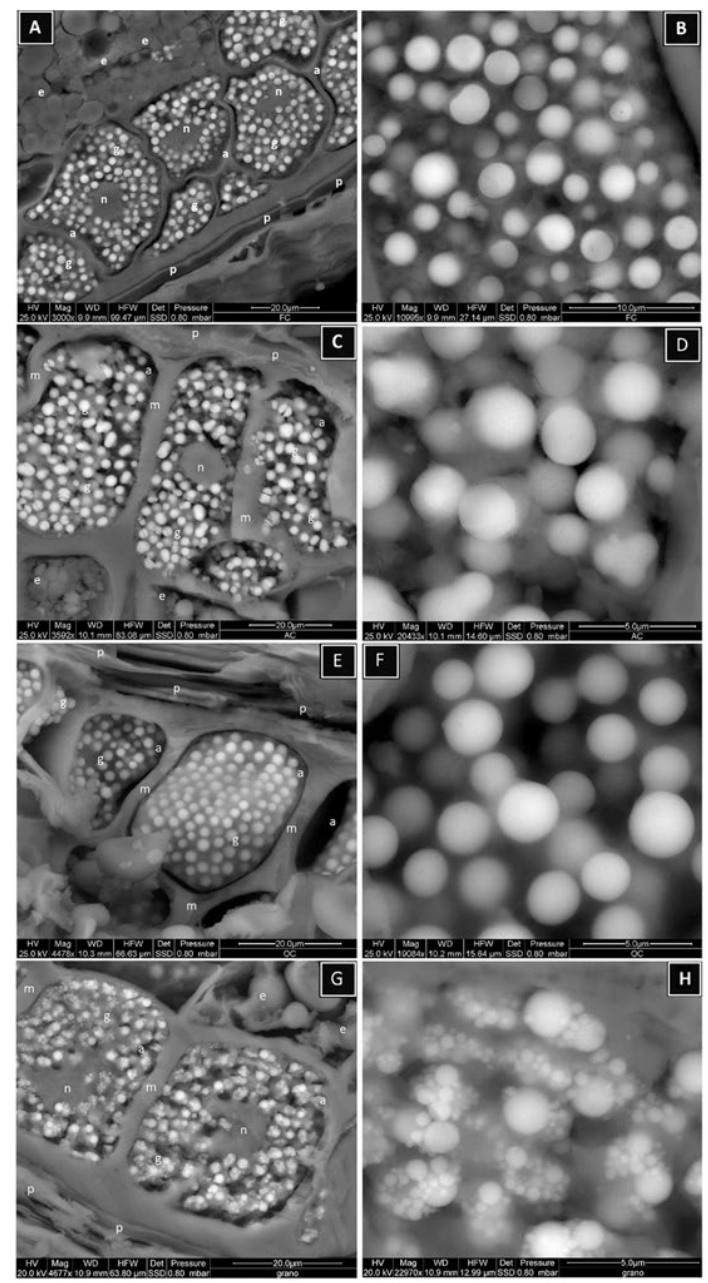

Fig. 8. ESEM backscattered electrons high magnification analysis of aleurone cells and aleurone protein granules in sectioned seeds of einkorn $(A, B)$, oat $(C, D)$, barley $(E, F)$ and wheat $(G, H)$. The aleurone cells (a) are fulfilled of bright granules $(g)$. Cell nuclei $(n)$ are often recognizable and cell membranes $(m)$ appear particularly thick, except in einkorn (A). The cell surfaces are strictly linked to the inner pericarp ( $p)$ as well as to the endosperm (e) (A, C, E, G. Bars: $20 \mathrm{\mu m}$ ). At higher magnification, the protein globules of einkorn (B), oat (D) and barley $(F)$ appear constituted by a homogeneous bright matter and shaped in round and smooth globules of different diameter. On the contrary, wheat aleurone protein granules $(H)$ are apparently constituted by globular subunits of different size and density, together clustered and surrounded by an amorphous, fine membrane. Bars: $B=10 \mu \mathrm{m} ; \mathrm{D}, \mathrm{F}, \mathrm{H}=50 \mu \mathrm{m}$. 
Fig. $9 \mathrm{~A}-\mathrm{H}$ shows the starchy endosperm, revealed by different ESEM analyses at different magnifications, using backscattered electrons images. In all the analyzed seeds, the endosperm appears constituted by granules that can be divided into two groups: large discoidal granules $(20 \mu \mathrm{m} \times 10 \mu \mathrm{m})$, and small spherical or polygonal granules (not exceeding $5 \mu \mathrm{m}$ of diameter of major side). In order to have precise information about the concentration of different sized granules, serial image analyses should be performed; nevertheless, our observational data suggest that a larger amount of large granules seems to be present in einkorn and barley (Fig. 9 A, B, E, F). An amorphous material appears as a link-system between the granules: in einkorn, oat and barley (Fig. 9, A-F). This material forms a delicate bridging that can be detected at high magnification only (Fig. $7 \mathrm{~B}, \mathrm{D}$, $F$ ), whereas in wheat (Fig. $9 \mathrm{G}$ and $H$ ) a denser and more compact amorphous material incorporates the granules. In the wheat samples, "footprints" of lost granules are frequently observed inside the endosperm (Fig. 9 H).

The morphological analysis at Atomic Force Microscopy (AFM) (Tab. 1) allows a better definition of the aleurone layer and the starch granules in the endosperm with new parameters, such as the roughness of the surfaces and the phase shift signal. The roughness describes how smooth the surface is whereas the phase shift is linked both to the chemical composition of the layer and to the orientation of the functional groups. We cannot go into the details of the AFM morphological analysis of the caryopsis, and for a more complete report the reader may refer to our recent publication (Antonini et al., 2018).

\section{CONCLUSIONS}

The present report shows that the morphological analysis of the caryopsis, performed with OM and ESEM-EDS, provides evidence of important structural differences among cereals. The aleurone layer and the germ are the most fragile points of breakage during processing. The thickness of the cell walls of the aleuronic cells plays an important role in the technological processing, such as pearling and malting. The endosperm, full of starch granules, conventionally divided into type A (larger) and type B (smaller), were clearly distinguished into compact or softer structures. 


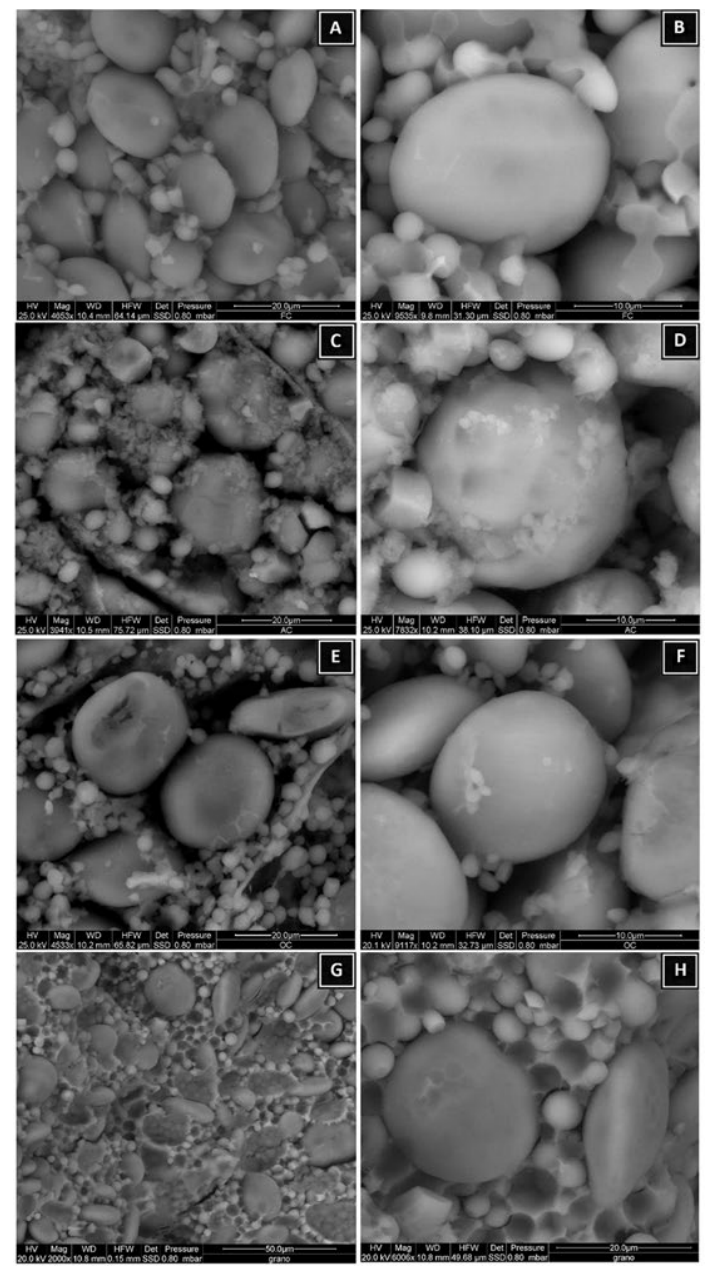

Fig. 9. ESEM backscattered electrons bigh magnification analysis of starchy endosperm and starchy globules in sectioned seeds of einkorn $(A, B)$, oat $(C, D)$, barley $(D, E)$ and wheat $(G, H)$. All the samples show in this area a compact organization of globules of different size. The gray level of the images is similar both for seed's kind and specimen's areas, this suggesting a similar chemical composition of low atomic number atoms $(A, C$, E, Bars: $20 \mathrm{\mu m} ; \mathrm{G}$, Bar: $50 \mathrm{\mu m}$ ). At higher magnification, the double size composition of the starchy granules is easily confirmed in all the samples. The main difference, related to the morphology of the granules clustering, is the presence of a delicate meshwork between the small and big size granules in einkorn, oat and barley (B, D, F, Bars=10 $\mu \mathrm{m})$. In wheat, this meshwork is substituted by a compact and abundant material that incorporates every single grain $(H, B a r=20 \mu m)$. 
With fluorescence OM, we obtained evidence of the presence of $\beta$-glucans and polyphenols, which are linked to the cellulose fibers. By ESEM-EDS, we provided a qualitative elemental composition of each region of the caryopsis.

The structures found in the caryopsis sections may be found in the flours and the derived products, as small but well identifiable fragments, whose frequency provides data for the identification of wholegrains versus refined products. In fact, most of the subcellular organelles are present into the wholemeal flour, i.e. the flour at $90-95 \%$ sieving rate. When the sieving rate is brought to less than $70 \%$, the loss of germ, protein, lipids and polyphenols in the bran are very relevant. This suggest to avoid refined flours in favor of wholegrain flours, as suggested in the HEALTHGRAIN project (van der Kamp et al., 2014).

To summarize, the utility of microscopy data on nutrition and technology lies in the following points:

1) Cereals with small-sized starch granules and thinner cell walls are more easily digested and absorbed than cereals with large starch granules and thick cell walls, due to their better bio-accessibility to amylase.

2) The density of the protein globoids and lipid bodies modulates the bio-accessibility and the absorption of nutrients. Protein bodies containing phytin and polyphenols hamper the action of amylase, thus increasing the digestion time. When proteases or lipases simultaneously work with amylase, the catalysis of each family of enzymes is slowed, with glycemic index depletion.

3) The elemental composition of the structures provides evidence of the mineral content, mainly $\mathrm{Ca}, \mathrm{Mg}, \mathrm{P}, \mathrm{Mn}$, which are important cofactors for the activity of several enzymes.

4) The thick cell walls of barley and, to a lesser extent, of oat maintain the caryopsis integrity during pearling and malting. Pearling is the process by which the caryopsis surface is smoothed to cook the cereal faster; malting is the wetting of the caryopsis in the dark to begin the germination for increasing the enzymatic content. These processes utilize a centrifugal force impressed on the cereals. In both cases, the broken caryopsis represent a loss of economical income and therefore cultivars with thick cell walls can be more conveniently processed.

Technologists and nutritionists can take advantage from this analysis, to provide suggestions to their direct coworkers and clients, in order to keep the nutrient level as high as possible for health protection. 


\section{AKNOWLEDGEMENTS}

The authors wish to thank the ARPAM, Pesaro Department (Pesaro PU, Italy) for collaboration with the University of Urbino "Carlo Bo" in the management of the the ESEM-EDS Laboratory.

\section{REFERENCES}

Antonini E, Diamantini G, Ninfali P. The effect of mechanical processing on avenanthramide and phenol levels in two organically grown Italian oat cultivars. J Food Sci Tech 2017:54:2279-87.

Antonini E, Lombardi F, Alfieri M, Diamantini G, Redaelli R, Ninfali P. Nutritional characterization of naked and debulled oat cultivar samples at harvest and after storage. J Cereal Sci 2016;72: 46-53.

Antonini E, Zara C, Valentini L, Gobbi P, Ninfali P, Menotta M. Novel insights into globoids of aleurone, starch granules and the outer layers of three cereals gained using atomic force microscopy and environmental scanning electronic microscopy. Eur J Histochem 2018;62: 20-7.

Deora NS. Whole wheat flour stability: An insight. Acta scientific nutritional health 2018; 2(3): 8-18.

Dornez E, Holopainen U, Cuyvers S, Poutanenen K, et al. Study of grain cell wall structures by microscopic analysis with four different staining techniques. J Cereal Sci, 2011; 54: 363-73.

EU 2012. Commission Regulation (EU) 432/2012. Establishing a list of permitted health claims made on foods, other than those referring to the reduction of disease risk and to children's development and health. Official Journal of the European Union 2012; 136: 1-40.

Fardet A. New bypotheses for the bealth-protective mechanisms of whole-grain cereals: what is beyond fibre? Nut Res Reviews 2010; 23: 65-134.

Fulcher RG. Fluorescence Microscopy of Cereals. Food Structure 1982; 1: 167-75.

Geng P, Harnly JM, Chen P. Differentiation of Whole Grain from Refined Wheat (T. aestivum) Flour Using Lipid Profile of Wheat Bran, Germ, and Endosperm with UHPLC-HRAM Mass Spectrometry. J Agric Food Chem 2015; 63: 6189-211.

Gibson GR and Roberfroid M. Dietary modulation of the buman colonic microbiota: introducing the concept of prebiotics. J Nutr 1995;125: 1401-1412.

Kasarda D. Can an Increase in Celiac Disease Be Attributed to an Increase in the Gluten Content of Wheat as a Consequence of Wheat Breeding. J Agric Food Chem. 2013; 61:1155-9.

Li M, Koecher K, Hansen L, Ferruzzi MG. Phenolic recovery and bioaccessibility from milled and finished whole grain oat products. Food \& Function 2016; 7: 3370-81.

Liu RH. Whole grain phytochemicals and health. J Cereal Sci 2007; 46: 207-19.

Mattila P, Pihlava JM, Hellstrom AMJ. Contents of Phenolic Acids, Alkyl- and 
Alkenylresorcinols, and Avenanthramides in Commercial Grain Products. J Agric Food Chem 2005; 53: 8290-5.

McKevith B. Nutritional aspects of cereals. Nutr Bull 2004; 29: 111-42.

Olsen OA. Endosperm development: Cellularization and Cell Fate Specification. Annu Rev Plant Physiol Plant Mol Biol 2001; 52: 233-67.

Panato A, Antonini E, Bortolotti F, Ninfali P. The histology of grain caryopses for nutrient location: a comparative study of six cereals. Int J Food Sci Tech 2017; 52: 1238-45.

Rosa-Sibakov N, Poutanen K, Micard VR. How does wheat grain, bran and aleurone structure impact their nutritional and technological properties? Trends Food Sci Tech 2015; 41: 118-34.

Silva EO, Bracarense AP. Phytic Acid: From Antinutritional to Multiple Protection Factor of Organic Systems. J Food Sci 2016: 81: R1357-62.

van der Kamp JW, Poutanen K, Seal CJ, Richardson DP. The HEALTHGRAIN definition of 'whole grain'. Food Nut Res 2014; 58: 1-10.

Zielinski H, Kozlowska H. Antioxidant Activity and Total Phenolics in Selected Cereal Grains and Their Different Morphological Fractions. J Agric Food Chem 2000; 48: 2008-16. 